\title{
From the Curtain to the Façade: Enhancing ESL/EFL Learners' Communicative Competence through an Interactive Digital Drama
}

\author{
Ivan Lombardi
}

\begin{abstract}
Façade is a one-act interactive digital drama about a marital crisis. The player is asked to play the role of a friend of the couple, and to try to cope with the situation by using his or her interaction skills. In this paper, I argue that Façade may be a valuable tool for teaching English as a second/foreign language, especially for the development of communicative competence. In order show how Façade may be used effectively, I (i) highlight the features of the tool that can play a meaningful role in language teaching; (ii) give examples of drama techniques that best exploit Façade; (iii) trace the techniques back to a methodology of reference; (iv) stress the primary importance of the human factor, the learners and teacher, over the technological tool. I then linger on the role of the teacher in activities that involve Façade, as well as other digital media. My proposal is presented under the metaphor of the edurector.
\end{abstract}

\section{Observing the Façade}

Façade $^{1}$ is a computer game (with a difference) developed by Michael Mateas and Andrew Stern. Since its release in 2005, it has been acknowledged as one of the most impressive AI-based digital participatory dramas (Hubbard 2002), especially praised for its plot, its natural processing of the English language feature, as well as the professional voice acting and the advanced 3D environment. In this paper, I intend to introduce this software and recommend its use in English language teaching as a tool to enhance communicative competence.

The goal of the whole Façade project is, in the programmers' words, to "create a compelling, well-written story that obeys dramatic principles, designed with many potential ways to play out" (Mateas \& Stern 2001: 1). In order to achieve this purpose, the chosen structure is that of a "domestic drama" (Mateas \&

\footnotetext{
1 Façade is a freeware software, and is available for download at http://www. interactivestory. net/download/.
} 
Stern 2005b: 665). The dramatis personae are Trip and Grace, a married couple in their early thirties (Mateas \& Stern 2004a), and of course the player, an old friend who has been invited to their house for a (supposedly) pleasant cocktail party. Apparently, Grace and Trip are a model couple, socially and materially successful. Shortly after the player's arrival, though, the player himself or herself becomes "entangled in the high-conflict dissolution of Trip and Grace's marriage" (Mateas \& Stern 2003: 3), and "unwittingly [...] an antagonist of sorts, forced by Grace and Trip into playing psychological 'head games' with them" (Mateas \& Stern 2005c: 2). Their marriage, as will soon be clear:

has been sour for years; deep differences, buried frustration, and unspoken infidelities have killed their love for each other. How the façade of their marriage cracks, what is revealed, and the final disposition of Grace and Trip's marriage, and Grace and the player's relationship, depends on the actions of the player (Mateas \& Stern 2005a: 21).

It will be up to the player to mediate between Trip and Grace, or to take sides; to play peacemaker, or to stir up hurt feelings - and let the cat out of the bag for good. Different interaction choices and actions will cause different events to be triggered. Consequently, the player can play through the interactive drama several times, and thus reveal alternative endings.

\section{Behind the Façade}

\subsection{Computer game vs. interactive drama}

Façade certainly shares major traits with digital games. From a technical, or even a semiotic point of view there is no significant difference: the Façade software runs on regular computer hardware (on both Windows and Macintosh operative systems), and needs no additional input device, other than keyboard and mouse. The on-screen objects allow the user to manipulate the relationships between objects and the environment (i.e. the principle of interactivity) and the inalienable, constitutive dichotomy between play and narrative ${ }^{2}$ is not only fulfilled, but also expressly planned and balanced by the authors:

[...] we explicitly wanted to push on the question of the compatibility of agency and narrative. This meant both creating an architecture that affords the authoring of non-linear, player-responsive narrative performed in real-time, and implementing a small but complete, high agency interactive drama within that architecture (Mateas \& Stern 2005a: 2-3).

\footnotetext{
2 Play and narrative are two definitional characteristics of a video game. Without the play dimension, the action on the screen would develop by itself with no user interaction - in the same manner as a movie; removing the narrative dimension would instead turn the game into a pointless (and certainly not fun at all) series of inputs and commands with no meaningful effect and no goal to achieve. It goes without saying that different video games, and video game genres, have different degrees of play and narrative features: arcade games like Pong or Tetris, as borderline examples, represent the smallest possible degree of story; adventures or role-playing games, instead, often reduce the play, the agency dimension to a minimum, while presenting long and complex screenplays and stories.
} 
Ultimately, what makes Façade a computer game with a difference is the random rule it involves. Like real actors, the characters on the screen can occasionally 'improvise' (i.e. the AI can randomly select conversation topics from a wide preprogrammed list). Grace and Trip can act and express themselves as believable agents, "autonomous characters exhibiting rich personalities, emotions, and social interactions" (Mateas \& Stern 2001: 1), virtual presences "with the ability to do several intelligent activities in parallel - for example, to gaze, speak, walk, use objects, gesture with their hands and convey facial expressions, all at the same time" (Mateas \& Stern 2004a: 2). The player has hardly any control over such 'spontaneous' behaviour - which is what ultimately supports replayability.

As Salen \& Zimmerman (2004) and Juul (2005) claim, video games cannot accept such an aleatory ${ }^{3}$ intervention of chance in gameplay. The enjoyment of playing a video game comes mostly from a personal challenge, from the struggle to achieve a goal which can only be accomplished by one's own ability to tackle obstacles, solve puzzles, and so on; the hazardous thrill of luck is a different kind of pleasure, and it cannot be in any way influenced by the player. By definition, the role of the player and his or her choices (i.e. cause-and-effect actions) are crucial. This means that chance and randomness are confined into a narrow, undefined space. Otherwise, the video game would only become frustrating:

To include forcedly aleatory elements [in a video game] means to risk provoking feelings of frustration. The maximum degree of unpredictability that a player can accept in a simulation, in fact, is basically close to the degree of imponderability implied in reality. If the intervention of chance in gameplay is not wisely calibrated, the risk of making the video game excessively easy or wildly difficult is high. This would consequently cause the video game to lose all of its appeal, and therefore the enjoyment it can provide the player (Lombardi, in press: 91).

Having said that, Façade proves not to be frustrating at all, and its occasional unpredictability ${ }^{4}$ is an integral part of the enjoyment it offers. This peculiar condition is made possible by the non-linearity of its narrative dimension. Unlike screenplays, which are determined from beginning to end, the underlying story in Façade flows on life-like rails, akin to a stage experience with real actors who are motivated to make a theatrically dramatic situation happen (Mateas \& Stern 2003). In IT terms, the simulation rules are in fact constantly revised, updated "in an attempt to give the player a well-formed overall experience with unity, efficiency and pacing" (Mateas \& Stern 2003: 6). The virtual synergy between such a non-linear fiction and the player agency - which, as previously stated,

\footnotetext{
${ }^{3}$ The French anthropologist and sociologist Roger Caillois, in his 1958 book Les jeux et les hommes, suggests a four-categories schema, a classification of games in which every category is represented by a main trait, a "play impulse": agôn (competition), alea (chance; hence the choice of aleatory in text), mimicry (simulation), ilinx (vertigo).

${ }^{4}$ Due to an 'algorithm of randomness', written in ABL [ebl], A Behavior Language, a language "specifically designed to support the creation of life-like computer characters (believable agents)" (Mateas Stern 2004a: 135).
} 
does not entirely fit in the definition of a digital game - can be thus called an interactive drama.

\subsection{Drama vs. interactive drama}

Since Laurel's 1986 pioneering work, interactive drama has been defined as a virtual world inhabited by fictional and computer-controlled characters, within which the player experiences a story from first person perspective - that is, through the simulacrum's 'eyes'. The identification process is consequently strengthened, and the player virtually mirrors his or her avatar: he or she assumes a new identity, which is distinct from his or her own (débrayage, see Lombardi, in press), but serves as a mediator to add a new layer of meaning to the performing action. The main character is therefore the player (meaning both contestant and actor), and his or her choices "deeply shape the path and outcome of the story, while maintaining a tight, author given story structure" (Mateas \& Stern 2005b: 645). An equilibrium is hence reached between free agency and a structured narrative in dramatic form, thus distinguishing such a peculiar digital pièce from other conceptions of video games or interactive stories $^{5}$.

The features discussed so far emphasize the role of interactivity - that is, the novelty factor with respect to traditional drama. The structure of an interactive drama, though, is definitely similar to the classical, Aristotelian structure of tragedy. It involves, as core elements: plot, character, diction, thought, spectacle and song (Aristotle, Poetics, 1450a; Laurel 1991; Mateas \& Stern 2005b). To explain how interactivity fits into this long-term established pattern, Mateas (Mateas \& Stern 2005b) resorts to three phenomenological categories - previously proposed by Murray (1998): immersion, agency, transformation. Immersion - "the feeling of being present in another place and engaged in the action therein" (Mateas \& Stern 2005b: 647) - is actually implied in the model by Aristotle: it is the necessary means for the spectator to experience $x^{\prime} \alpha \vartheta \alpha \rho \sigma \iota \varsigma$ (katharsis). Transformation is embodied in this model, too, in the form of change in the protagonist. According to Mateas \& Stern (2005b: 648), then:

While immersion and transformation exist in some form in non-interactive drama, the audience's sense of having agency within the story is a genuinely new experience enabled by interactivity.

Agency, in Murray's terms, can be described as "the satisfying power to take meaningful action and see the results of our decisions and choices" (Murray 1998: 126), which is conceptually different from interaction. The latter is, in fact, a collaborative participation in an event - in the history of drama, it is nothing new, as the structure of a theatre of interaction is well established and especially common nowadays. The former, agency, has instead been made

\footnotetext{
${ }^{5}$ Not surprisingly, since the publication of Computers as Theatre (Laurel 1991), interactive digital dramas have been included in several projects and experimentations for language teaching and learning - see Bacon et al. (1993), Hubbard (2002), Carroll (2009).
} 
possible by computer technology, which allows the player to have a decisive impact, a crucial effect on the virtual environment, thus dramatically reshaping the direction of the narrative. Through interactivity, the player has the ability to control almost every element on the stage within the canovaccio - the fundamental structure of story.

In order to integrate agency into Aristotle, Mateas (Mateas \& Stern 2005b: 649) introduces the player as a key element in the character category. Therefore, "[b]y taking action in the experience, the player's intentions become the formal cause of activity happening at the levels from language down to spectacle". Diction, thought, song and spectacle, then, represent the material resources for the player to act, the elements available ${ }^{6}$ for him or her to play with.

\section{Cracking the Façade}

\subsection{The communicative core: natural English language processing}

In an interactive drama, and in Façade especially, diction (language) is the key for player intervention, and it is intended as a way to build the story, to guide the dramatic event through different development courses (see section 1.2). It can be said that the player becomes the playwright, the cause of the plot, by expressing his or her intentions and sharing them with the virtual characters.

Unlike many other similar projects, whose interactivity is allowed by interfaces with predetermined interaction cues and actions (Hubbard 2002), Façade allows the player to type a line, in English, with his or her keyboard. The AI will then deploy a natural language processing tool (NLP, thoroughly described and explained in Mateas \& Stern 2004b) to recognize the meaning and answer, both verbally and non-verbally, in a coherent manner. As a result, a believable dialogue is produced:

Dialog is a powerful means for characters to express their thoughts, thus instrumental for helping the player to infer a model of the characters' thoughts. Conversely, dialog is a powerful means to influence character behavior. If the experience makes dialog available to the player (and most contemporary interactive experiences do not), this becomes a powerful resource for expressing player intention (Mateas \& Stern 2005b: 650).

Language - in its broadest sense, which also includes body language - is mostly deployed as a dialogue between the player, typing communicative inputs, and the two interlocutors, providing audio-visual and kinaesthetic feedback, as well as new conversational inputs when needed. In order to conform to the player's expectations, AI-controlled linguistic-communicative statements play on one

\footnotetext{
${ }^{6}$ Availability shall here be understood in parallel to the notion of affordance in usability. According to Norman (1988), the term affordance depicts the sum of qualities that an object, an environment, an interface bears in itself, allowing a user to perform an action. A button, for example, affords pushing and will not afford twisting. By availability I therefore mean the affordance, the potential that said material resources have to produce action.
} 
main peculiarity: the focus on responding to the pragmatic effects of language ("what a language utterance does to the world", Mateas \& Stern 2004b: 1), rather than on the written form of the text (i.e. its morphosyntax; this choice also allows the dialogue management system to overlook a few typos and $\mathrm{BrE} / \mathrm{AmE}$ spelling differences) or its semantics. For example,

if the player types 'Grace isn't telling the truth', the NLP system is responsible for determining that this is a form of criticism, and deciding what reaction Grace and Trip should have to Grace being criticized in the current context (Mateas \& Stern 2004b: 1).

In the field of applied linguistics, this underlying mechanism of determining pragmatic pattern is commonly referred to as speech act (Wilkins 1976) recognition.

Practically and essentially, the conversation in Façade takes place in (pseudo) real-time (keyboard input $\rightarrow$ processing [in the order of milliseconds] $\rightarrow$ dramatic response). The virtual characters' linguistic-communicative abilities are perceptively well-structured, as they can talk widely around the central topic of the story. They can also understand (technically: process) a reasonably large variety of off-topic remarks from the player, as long as they contain a speech act - e.g. to greet, to thank, to ask, to insult, and so on.

From a perceptive point a view, the above-mentioned verb talk is appropriate. An additional feature of the interaction in Façade is, in fact, Grace and Trip's professional voice acting, supplied respectively by actors Chloe Johnston and Andy Bayiates ${ }^{7}$. It is also worth emphasizing that speech chunks are preeminently oral. Subtitles are not available.

\subsection{Design features and proxemics in Façade}

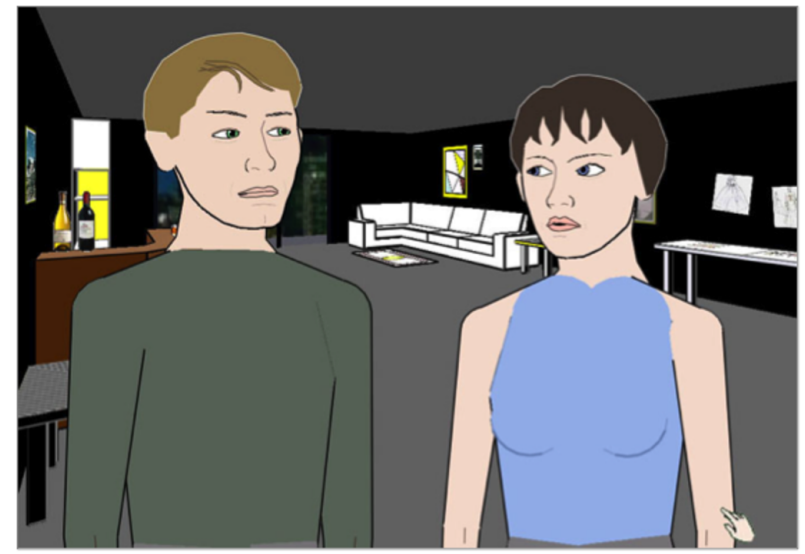

Figure 1: Trip and Grace, viewed from first-person perspective

On-screen objects are designed for interaction (in form of manipulation, collecting, observation) and avail (see footnote 5) the physical element of the

7 See: http://ww. interactivestory.net/faq/. 
drama. The player can navigate in the environment and interact with objects (e.g. drinks, pictures) via keyboard and mouse - the latter also being used as a trigger for non-verbal communication with the virtual characters: gestures, touching, hugging, kissing. Thus, the proxemics of the dramatic event is integrated into the architecture of the software. Ultimately, the design (which includes both the architecture and the game mechanics) of Façade is also a formal constraint, in the sense that it indirectly tells the player what he or she will and will not be able to do on stage. It provides

the material resources for action at the level of spectacle [as well as] a clean, transparent interface [which] insures that agency (and thus immersion) will not be disrupted (Mateas 2004: 27).

\section{Façade as a tool to enhance English language competence}

When I first played Façade, back in 2006, I had fun - which is, of course, fundamental. I found myself employing my whole communicative competence in English, and putting a huge effort into achieving the most absurd situations, the funniest reactions, the most different endings I could imagine. I went on until I exhausted poor Trip and Grace with my pertinacity and unpredictability. As I embroiled friends and colleagues in playing this interactive drama, I noticed that the attitude was common. Furthermore, being a non-native speaker seemed to add a tad of intrinsic motivation and pleasure in controlling the dramatic virtual environment. Therefore, I started to work on the in-built language teaching potential of Façade, and developed suitable techniques, which I traced back to a productive methodology. This methodology is intended to exploit the mechanism of interaction for the enhancement of ESL/EFL learners' linguistic-communicative skills (as defined in Kao \& O'Neill 1998).

\subsection{Towards a ludic methodology for language education}

According to Kumaravadivelu (2009: 84), the term methodology refers to "what practicing teachers actually do in the classroom in order to achieve their stated or unstated teaching objectives". Similarly, the Italian tradition of language education studies defines the methodology as "a collection of principles and actions that aim to a didactic end" (Lombardi 2012: 3). Within the same tradition, the methodology is integrated into the hierarchical framework proposed by Balboni (2006), which is largely based on Anthony's three-tier framework (1963). In Balboni's model, the methodology is juxtaposed with the approach on the one side, and with the techniques on the other. The approach ultimately represents the underlying teaching philosophy; instead, techniques are the single practical actions that a teacher may undertake to reach his or her didactic aims. Not surprisingly, the latter term is often in the plural form: a methodology will always include and integrate more than one technique. 
In order to achieve their aims effectively, techniques need proper tools. The role of Façade will just be that of a tool, which can be integrated into several techniques, all adhering to the dictates of a ludic methodology (cf. Caon 2006).

Ludic, as stated in Lombardi (2012: 3) "does not (just) mean 'playful', it also involves the philosophical and anthropological concept of ludicity", as described by Conceição Lopes (2005; 2008), Rutka (2006) and Lombardi (2012, in press). Ludicity should be understood as a state, "not just characteristic of childhood, but [...] shared by all age groups" (Conceição Lopes 2005: 3), which mirrors the flow-like behaviour in games: "an intrinsic attitude characterized by gratuitousness, liberty, enjoyment, creativity, relationship with the world around" (Lombardi 2012: 3).

Developing language skills with a ludic methodology does not generally mean having fun; of course, if tools and techniques contribute to enjoyment as to education (like Façade hopefully should), so much the better. Ludic learning, instead, is bound to:

respect this fundamental state of humankind, which since the early childhood stands up as the main resource for discovering, experiencing, growing up [...] - the cornerstones of education in its broadest sense (Lombardi 2012: 3).

Briefly, the main principles of this methodology are:

- attention to learning environments;

- centrality of learners;

- meaningful learning (as outlined in Novak 1998);

- multi-sensuous engagement;

- pluriculturalism and cultural relativism (i.e. the awareness that every language, and thus every culture has its own traits - and different traits do not justify value judgements. Cultures cannot be better or worse, only different).

Techniques that fit into such guidelines should be able to enrich communicative competence (Liu 2002).

Enhancing learners' communicative competence means helping learners improve not only their knowledge of linguistic notions and formal grammar (linguistic sub-competence), but also developing parallel sub-competences, which are as important as the former. I am mainly referring to paralinguistic and extralinguistic sub-competences, i.e. the consciousness of the key role that paralanguage and non-verbal communication, respectively, play in interactions. Furthermore, the idea of communicative competence entails the socio-pragmatic sub-competence - the knowledge of cultural prerogatives, of accepted social practices, of diatopic, diastratic and diaphasic variations, and so on ${ }^{8}$.

8 This paradigm of communicative competence, formulated by Balboni (2006), is grounded 


\subsection{Possible uses of Façade in the language classroom}

Façade may help to introduce ludic patterns into known teaching techniques and established good practices. Here I will focus on three examples: role play (i), open dialogues (ii) and role making (iii). Further collections of drama-based techniques for language learning that might gain new life blood thanks to Façade may be found in Holden (1981), Dougill (1987), Kao and O'Neill (1998), Burke and O'Sullivan (2002) and Maley and Duff (2005).

With role play techniques (i), learners are meant to play one role on the basis of a draft. The draft usually points out the communicative situation, as well as its pragmatic purpose. The purpose may be either invented by the students and self-imposed, or dictated by the teacher. Façade may be used to provide both the situation and a goal to achieve. Learners will be catapulted into the interactive story and should be encouraged to creatively build the dramatic event, with the aim of reaching a specific pre-negotiated goal (e.g. to bring Trip and Grace back together). As students are free to choose their own way to reach the pragmatic purpose, their production of communicative acts will be subordinated to their will and to their ability to interact in the target language (cf. Kao and O'Neill, 1998) - thus allowing the teacher to evaluate the learners' capability to achieve a given communicative goal.

Open dialogues (ii) imply that the learner knows the context and situation of the dialogue, as well as the other characters involved in the interaction. The learner is then asked to react to the communicative inputs that interlocutors provide. He or she still plays an active and leading role, but his or her competence is mainly put to the test in reference to the adequacy of answers and reactions during the conversation. As stated above (see sections 1.2 and 2.2), the characters in Façade are life-like, that is they can move, act and talk independently, like real people. They can also choose (from a closed, but still perceptively huge set) a conversational path to change topic, break the silence and avoid awkward moments. Exploiting these peculiarities with open dialogue techniques means treasuring the flexibility and the adaptability of the software, in order to recreate believable communicative acts. The dialogues thus created are driven by the virtual characters, and are therefore initially unpredictable for the student: he or she has to face a situation which is not predetermined, and has to advance through the story and eventually manage to reach an ending. The didactic aim of this activity is to allow learners to try out their command of the English language (cf. Balboni 2008). The teacher may interpret the results to get feedback on the learners' linguistic-communicative effectiveness and autonomy in a situation which is perceived as realistic ${ }^{9}$.

firmly in previous language teaching theories. It moves from Hymes' classical definition (Hymes 1967), integrates the components highlighted by Canale and Swain (1980) and takes into account later revisions of the concept, like the ones collected by Angelis and Henderson (1989). It also adds several insights on the socio-cultural and pragmatic sub-competences, which have been studies thoroughly by the Venetian school of language teaching methodology in the last twenty years.

${ }^{9}$ Clearly, the situation is not 'real', because it takes place in a virtual environment. Still, the 
Role making (iii) gives the student full responsibility for the interaction: purpose, communicative acts, psychological key, genre, norms. In game terms, full responsibility is equivalent to free play, which can be translated, in Façade, as interaction without set limits. This means that the learner leads the dramatic conversation and may route and detour it at will: he or she might (consciously or unconsciously) change his or her goal; try different approaches towards the situation; switch between taking Grace's or Trip's side; abruptly change register and/or attitude towards the characters. Briefly, the player/learner can refine communicative strategies and negotiation skills in an environment that provides constant feedback, and at the same time helps to reduce the level of emotionality involved in drama-based activities - the latter being a peculiarity of written techniques, like the ones in which Façade can play a major and meaningful role. Moreover, since they require a free and active stand on behalf of the learners, such techniques often lead to a flow state (Csikszentmihalyi 1990) and possibly to a final shift in the focus, from English as a target language to the use of English as a medium to achieve a goal.

In role making, the role of the teacher is not marginal at all. He or she will have to supervise the didactic action, and, most of all, will need to encourage post-activity discussions: comparisons, exchange of strategies and practices, problems faced and critical situations handled, remarks and considerations, afterthoughts. Reflecting on the techniques used with the students is a nonoptional moment of techniques themselves. Quite the contrary, this moment provides feedback on whether teaching objectives have been achieved or not.

\subsection{The Human Factor: learner - edurector}

In the context of the ludic methodology for language education, the learner plays an active and pivotal role (see section 4.2). He or she is asked to be the protagonist of his or her learning process. Clearly, the learner will only be able to take control of it on the operational level of techniques, by interacting with tools and manipulating teaching materials. In order to play the main role in Façade, the player needs to be able to use his or her interaction skills in English. In addition, the player should be well aware of his or her personal ability in interaction, i.e. the set of cognitive processes, communicative strategies and rules that allow dialogues to be established. For this reason I have included, within the methodological paradigm, the interactive drama among the tools which may be effective with advanced learners of English as a second or foreign language. Beginners, in fact, may not just lack the vocabulary to interact: they also might have not yet developed the capability to manipulate communicative acts autonomously - and may therefore perceive the task demanded by Façade as overwhelming, and be frustrated.

In my opinion, Façade may be a valuable tool when used with learners who

experience is real, as it takes place within the player. What happens in a digital space is always meaningful to the user - otherwise, digital products could not be perceived as "compelling" (Mateas Stern 2001: 1), as worth spending time and energy on. 
can at least:

interact with a degree of fluency and spontaneity that makes regular interaction with native speakers quite possible without strain for either party. [Who] Can produce clear, detailed text on a wide range of subjects and explain a viewpoint on a topical issue giving the advantages and disadvantages of various options (Council of Europe 2001: 24).

The above-mentioned description refers to the B2 level of the Common European Framework of Reference for Languages. A B2-level learner is described as an independent user and, with reference to interactive abilities, should be able to:

initiate discourse, take his/her turn when appropriate and end conversation when he/she needs to, though he/she may not always do this elegantly. Can help the discussion along on familiar ground confirming comprehension, inviting others in, etc (Council of Europe 2001: 28).

Should the teacher find that his or her pupils are below the B2 level, he or she must be aware that techniques involving the use of Façade may be unsuitable to the classroom or group of learners. On the other hand, if some pupils demonstrate clear autonomy when discussing and in dialogues, while some others do not, the teacher should see this heterogeneity as an opportunity and take advantage of it. He or she should try to create working pairs (or groups of three people, at most) among the pupils, possibly grouped mixing different levels of experience with digital games or dramas, as well as gender, character, cognitive style - and confidence in their communication skills in the second language. Pairs are probably the best solution in order for positive social dynamics, such as peer cooperation and mutual help (cf. Egenfeldt-Nielsen 2007), to occur - though they do not magically create a stronger learning experience by themselves.

Since the rise of communicative approaches in the 1970s (cf. Mitchell \& Miles 2004), the idea of a magister ex cathedra has been challenged. The ludic methodology for language learning, which is in great measure an application of humanistic approaches, is on the same wavelength, and is based on the notion of the teacher as facilitator. Within this methodology, the task of a facilitator is:

- to create a context wherein the pupil can learn the language in a diffused playfulness;

- to adopt a varying and negotiable didactic that adapts itself to the characteristics of the learning group, which then in turn adapts itself to different learning modalities that favour diverse cognitive styles and that encourage an interaction among the members of the group;

- to program activities that permit the conciliation of disciplinary contents with the students' interests and that favour their learning modalities, and second, that supply the scaffolding, the support, and the incentive for the development of linguistic-communicative, expressive, cognitive, social, and intercultural competence (Caon 2006: 49-50). 
In addition, the teacher should create a meaningful relationship with the students.

When working with digital media, the metaphor of the edurector (Lombardi 2012; in press) is probably an efficient embodiment of the above-mentioned notion. Edurector is a portmanteau for educator and director. The teacher is required to become an educator in the sense that his or her aim should be not only to transmit vocabulary and highlight the grammar of a second or foreign language. An educator should integrate teaching with particular attention to the pupils' personal sphere: their learning styles, interests, motivation, future goals. Hopefully, with this information the teacher/educator will be able to offer a more customized (i.e. personally meaningful for the student) learning experience.

A teacher becomes a director when he or she:

Directs the "players", i.e. looks after students, supports their motivation, points their attention towards elements of significance, watches over involved social dynamics, holds the reins on the group, suggests and organizes activities, and shares with "actors" the responsibility for the fulfilment of established didactic ends (Lombardi 2012: 4).

In techniques that use Façade, then, the teacher will not fade away and be subordinate to the interactive tool. His or her role will still be vital, as a negotiator of didactic goals, a motivator, a counsellor - and, from time to time, a prompter, too.

\section{Conclusion}

Within the established paradigm of the ludic methodology for language education, I have proposed the interactive drama Façade as a tool to enhance the communicative skills of advanced learners of English as a second/foreign language. I have pointed out how the tool influences teaching and how it should be used with respect to the main actors in the "field of didactic action" (Balboni 2007: 33): student, teacher, language. So far, my research has been conducted mainly on the theoretical apparatus. Future work should focus on application and experimentation in schools and universities as well as conducting empirical research into the effectiveness of Façade. Both the methodology and related techniques will surely benefit from data collected by means of field work.

\section{Bibliography}

Angelis, Paul; Henderson, Thelma (eds.) (1989): Selected papers from the proceedings of the BAAL/AAAL joint seminar "Communicative Competence Revisited" held at the University of Warwick, 8-10 July 1988. In: Applied Linguistics, 10/2, 113-250 
Anthony, Edward M. (1963): Approach, Method, and Technique. In: ELT Journal 2, 63-67

Bacon, Richard M.; Baolin, Ma; Goldfield, Joel D. $\left(1993^{2}\right)$ : The Thunder and Lighting Professor: Teaching Language by Using Theater Plus Up-to-the Minute Technology In: Oller, John W. (ed.): Methods That Work: Ideas for Literacy and Language Teachers. Boston: Heinle \& Heinle, 40-49

Balboni, Paolo E. (2006): The Epistemological Nature of Language Teaching Methodology. Perugia: Guerra

Balboni, Paolo E. (2007): Operational Models for Language Education. Perugia: Guerra

Balboni, Paolo E. (2008): Fare educazione linguistica. Attività didattiche per italiano L1 e L2, lingue straniere e lingue classiche. Torino: UTET Università

Burke, Ann F.; O'Sullivan, Julie C. (2002): Stage by Stage: A Handbook for Using Drama in the Second Language Classroom. Portsmouth, NH: Heinemann

Caillois, Roger (1958): Les jeux et les hommes. Le masque et le vertige. Paris: Gallimard

Canale, Michael; Swain, Merrill (1980): Theoretical Bases of Communicative Approaches to Second Language Teaching and Testing. In: Applied Linguistics, 1/1, 1-47

Caon, Fabio (2006): Pleasure in Language Learning. A Methodological Challenge. Perugia: Guerra

Carroll, John (2009): Point of View: Linking Applied Drama and Digital Games. In: Anderson, Michael; Cameron, David; Carroll, John (eds.): Drama Education With Digital Technology. New York: Continuum, 81-96

Csikszentmihalyi, Mihalyi (1990): Flow: The Psychology of Optimal Experience. New York: Harper Collins

Conceição Lopes, Maria da (2005): Ludicity - a Theoretical Term, paper presented at the Sixth Annual Convention of Media Ecology Association "The Biases of Media". URL:

http://www.tasplay.org/taspfiles/pdfs/lopesludicitypaper.pdf (last accessed: 6/12/2012)

Conceição Lopes, Maria da (2008): Ludicity: a theoretical horizon for understanding the concepts of game, game-playing and play. In: Stanfield, Mark; Connolly, Thomas (eds.): 2nd European Conference on Game Based Learning Proceedings. Reading: Academic Publishing Limited, 275-284

Council of Europe (2001): Common European Framework of Reference for Languages: Learning, Teaching, Assessment. Cambridge: Cambridge University Press. On-line version available at:

http://www.coe.int/t/dg4/Iinguistic/Source/Framework_EN.pdf (last accessed: 6/12/2012)

Dougill, John (1987): Drama Activities for Language Learning. London: Macmillan 
Egenfeldt-Nielsen, Simon (2007): Educational Potential of Computer Games. New York: Continuum

Fyfe, William Hamilton (1932): Aristotle in 23 Volumes, vol. 23. London: William Heinemann Ltd

Hymes, Dell (1967): Models of the Interaction of Language and Social Setting. In: Journal of Social Issues, 22/2, 8-38

Holden, Susan (1981): Drama in Language Teaching. Harlow: Longman

Hubbard, Philip (2002): Interactive Participatory Dramas for Language Learning. In: Simulation \& Gaming 33/2, 210-217

Juul, Jesper (2005): Half-Real: Video Games between Real Rules and Fictional Worlds. Cambridge, MA and London: MIT Press

Kao, Shin-Mei; O'Neill Cecily (1998): Words into Worlds: Learning a Second Language Through Process Drama. Stamford, CT: Ablex

Kumaravadivelu, B. (2009): Understanding Language Teaching: From Method to Postmethod. New York-London: Routledge

Laurel, Brenda (1991): Computers as Theatre. Reading, MA: Addison-Wesley

Laurel, Brenda (1986): Towards the Design of a Computer-Based Interactive Fantasy System. Submitted in part fulfilment of the requirements for the degree of Doctor of Philosophy, Department of Theatre, theory and criticism, The Ohio State University, Ohio. Unpublished Ph.D. Thesis

Liu, Jun (2002): Process Drama in Second- and Foreign-Language Classrooms. In: Bräuer, Gerd (ed.): Body and Language: Intercultural Learning through Drama. Westport, CT: Ablex, 51-70

Lombardi, Ivan (2012): Computer Games as a Tool for Language Education. In: $G|A| M \mid E$. Games as Art, Media, Entertainment, 1/2012.

http://www.gamejournal.it/computer-games-as-a-tool-for-

language-education/ (last accessed: 6/12/2012)

Lombardi, Ivan (in press): Game [not] over. I videogiochi come strumenti per la glottodidattica ludica. Perugia: Guerra - Strumenti dell'AItLA

Maley, Alan; Duff, Alan $\left(2005^{3}\right)$ : Drama Techniques. A resource book of communication activities for language teachers. Cambridge: Cambridge University Press

Mateas, Michael (2004): A Preliminary Poetics for Interactive Drama and Games. In: Wardrip-Fruin, Noah; Harrigan, Pat (eds.): First Person: New Media as Story, Performance, and Game. Cambridge, MA: MIT Press, 19-33

Mateas, Michael; Stern, Andrew (2005a): Build It to Understand It: Ludology Meets Narratology in Game Design Space. Proceedings of DIGRA 2005 Conference "Changing Views - Worlds in Play". URL:

http://www.digra.org/dl/db/06278.41489.pdf, unpaged (last accessed: $6 / 12 / 2012)$

Mateas, Michael; Stern, Andrew (2005b): Interaction and Narrative. In: Salen, Katie; Zimmerman, Eric (eds.): The Game Design Reader: A Rules of Play Anthology. Cambridge, MA: MIT Press, 642-669 
Mateas, Michael; Stern, Andrew (2005c): Structuring Content in the Façade Interactive Drama Architecture. Proceedings of AIIDE 2005 Conference "Artificial Intelligence and Interactive Digital Entertainment". URL: http://www. interactivestory . net/papers/MateasSternAIIDE05.pdf, unpaged (last accessed: 6/12/2012)

Mateas, Michael; Stern, Andrew (2004a): A Behavior Language: Joint Action and Behavioral Idioms. In: Prendinger, Helmut; Ishizuka, Mitsuru (eds.): Life-like Characters. Tools, Affective Functions, and Applications. Berlin-Heidelberg-New York: Springer, 135-161

Mateas, Michael; Stern, Andrew (2004b): Natural Language Understanding in Façade: Surface-Text Processing. Paper presented an TIDSE 2004 "Technologies for Interactive Digital Storytelling and Entertainment". URL: http://www. interactivestory . net/papers/MateasSternTIDSE04.pdf, unpaged (last accessed: 6/12/2012)

Mateas, Michael; Stern, Andrew (2003): Façade: An Experiment in Building a Fully-Realized Interactive Drama. Paper presented at GDC 2003 "Game Developers Conference - Game Design Track". URL: http://www. interactivestory. net/papers/Mateas.SternGDC03.pdf, unpaged (last accessed: 6/12/2012)

Mateas, Michael; Stern, Andrew (2001): Towards Building a Fully-Realized Interactive Drama. Paper presented at DAC 2001 "Fourth International Digital Arts and Culture Conference". URL: http:

//www.stg.brown.edu/conferences/DAC/abstracts/mateas_stern.html, unpaged (last accessed: 6/12/2012)

Mitchell, Rosamond; Myles, Florence $\left(2004^{2}\right)$ : Second Language Learning Theories. London: Hodder Arnold

Murray, Janet H. (1998): Hamlet on the Holodeck. Cambridge (MA): MIT Press

Norman, Donald A. (1988): The Psychology of Everyday Things. New York: Basic Books

Novak, Joseph D. (1998), Learning, Creating, and Using Knowledge: Concept maps as facilitative tools for schools and corporations. Mahwah, NJ: Lawrence Erlbaum

Rutka, Sonia (2006): Non solo giochi: il concetto di ludicità. In: In.It, 19/2006: 11

Salen, Katie; Zimmerman, Eric (2004): Rules of Play: Game Design Fundamentals. Cambridge, MA and London: MIT Press

Wilkins, David A. (1976): Notional Syllabus. Oxford: Oxford University Press 